\title{
The Comprehensive Approach: NATO Responses from an Operational Standpoint - The Case of Afghanistan
}

\section{Ambassador Adam Kobieracki *}

International operations undertaken since the early 1990s have underscored the desirability, indeed the requirement, for a broader approach to crisis management and conflict resolution. Such a 'comprehensive approach' would bring together, early in a crisis situation, military and non-military instruments aimed at conflict prevention, stabilization and reconstruction, as well as governance and development depending on circumstances. These contributions would be provided by the International Community in a concerted manner and in close coordination with the host government. Many elements of such a Comprehensive Approach are already in place and are being applied in various theatres around the world, albeit often in an ad hoc and sub-optimal way. Maybe the novelty of the concept of a Comprehensive Approach is the added emphasis on enhancing planning and optimizing implementation in the conduct of stabilization operations and reconstruction efforts.

NATO has been conducting operations continuously since 1992, first in the Balkans and since 2003 outside of Europe. Almost universally, lessons identified from NATO-led operations in Bosnia and Herzegovina, Kosovo and Afghanistan, as well as the NATO disaster relief operation in Pakistan in 2005 and NATO's support to the African Union in Darfur, have shown that NATO is present in a theatre not alone, but together with other actors of the International Community. They have also highlighted the benefits of early and continuous consultation and cooperation between the Alliance and other international organizations, both intergovernmental and non-governmental, present on the ground. As a result, at the Riga Summit meeting held in November 2006, NATO's Heads of State and Government decided that NATO should develop, as a matter of urgency, a policy, as well as procedures, to guide NATO's contribution to a Comprehensive Approach, with direct application in Afghanistan and Kosovo. It is important to note in this regard that the philosophy underpinning NATO's approach to the further development of its contribution to a wider Comprehensive Approach is that NATO should endeavor to co-ordinate with other international organizations, not coordinate them.

Additionally, at the summit, NATO Heads of State and Governments endorsed new Comprehensive Political Guidance (CPG). The CPG provides a framework for NATO's ongoing transformation and sets out the priorities for Alliance capability issues. In this important document, the contribution of a Comprehensive Approach with other international organizations to operations is mentioned, pointing out 'the increasing significance of stabilization operations and of military support to post-conflict re-

Ambassador Adam Kobieracki is NATO Assistant Secretary General for Operations. This article is dedicated to the Comprehensive Approach to Modern Conflict Conference, sponsored by the G.C. Marshall European Center for Security Studies, 26-27 March 2007. 
construction efforts.' The CPG and the on-going work on developing NATO's contribution to a Comprehensive Approach reflect a growing recognition among the Allies of the importance of the civil-military interface both on the ground and at NATO HQ Brussels.

NATO's intentions, therefore, are clear although not always well understood. Finding consensus on the scope of an International Community-wide approach is not facilitated by the fact that different nations and international organizations have, for a host of reasons, different visions of what a Comprehensive Approach should be and opinions of how it should be implemented in practice. What is clear is that, almost irrespective of circumstances, mandates and local conditions, the provision of security is a key enabler for efforts aimed at governance, reconstruction and development and, therefore, developing greater synergy between these pillar is for the Alliance, as a leading provider for security, of critical importance.

The focus of this article is on Afghanistan, but several of the points raised below are also applicable to Kosovo and other theatres.

NATO recognizes that its politico-military engagement in Afghanistan should be guided by a Comprehensive Approach that brings together NATO's military involvement in theatre with the Alliance's wider diplomatic efforts, in concert with other partners, to facilitate progress in implementing the Afghanistan Compact agreed in London in February 2006. These wider efforts encompass a range of initiatives and activities:

1. assisting the Government of Afghanistan (GoA) in strengthening its authority and presence across the country;

2. facilitating the execution of Security Sector Reform (SSR) by the G-8 lead nations (Germany; Italy; Japan; the United Kingdom; and the United States);

3. helping set the security conditions for implementing the Afghan National Development Strategy (ANDS); and

4. promoting intra-regional dialogue and co-operation between Afghanistan and its neighbors, including Pakistan and the NATO Partnership for Peace nations of Central Asia.

In support of these, NATO and Afghanistan agreed a program of cooperation in September 2006 that addresses a range of Afghan needs in terms of defense reform and institution building and defense education.

NATO is aware that continuous and close cooperation with Afghan leaders and other international actors is key to success. To that end, NATO has been inviting other international organizations, such as the UN, the EU and the World Bank, to ministerial and ambassadorial meetings at NATO Headquarters in Brussels to exchange views and deepen cooperation.

As a result of these initiatives, NATO's engagement in Afghanistan is now a multipronged effort, spanning the political and military spheres. Since August 2003, when NATO took command of ISAF, the Alliance has had an expanding commitment to Afghanistan, in accordance with successive UN Security Council resolutions. ISAF remains the centerpiece of NATO's engagement and comprises now nearly 35,000 
troops from all 26 Allies and 11 non-NATO nations, which are deployed across the country, up from less than 5,000 in and around Kabul only in 2003. ISAF's command structure includes ISAF HQ in Kabul, five regional commands and 25 Provincial Reconstruction Teams (PRTs). It is truly a multinational effort. The number of ISAF contributing nations is expected to grow shortly, as other non-NATO nations join the Force.

In line with the ISAF operations plan (OPLAN), the mission of ISAF is to provide security assistance through the establishment of a safe and secure environment, the build up of the Afghan National Security Forces, and the extension of governance and the rule of law, including through the disarmament of illegally armed groups (DIAG) and the enhancement of counter-narcotics efforts led by the Afghan Government, the United Nations and the United Kingdom. Central elements of these ISAF tasks are helping with the training and equipping of the Afghan National Army, notably through the training of Afghan National Army kandaks (battalions) by deployed Operational Mentoring and Liaison Teams (OMLTs), the mentoring of the Afghan National Police, and the improvement of border security.

Provincial Reconstruction Teams are at the frontline of NATO's efforts. PRTs are mixed civil and military teams of military personnel and civilian experts from ISAF nations. PRTs are a useful local anchor for the international presence in Afghanistan, bringing that presence closer to villagers, particularly in remote parts of the country. The synergy provided between the provision of security by the military and reconstruction by the civilian element, in concert with the local and national Afghan authorities, the United Nations Assistance Mission in Afghanistan, and non-governmental organizations (NGOs), is, in a microcosm and imperfectly, a model of the Comprehensive Approach 'in action.' There is nearly universal agreement, however, that for PRTs to be truly effective, they must increasingly have a civilian face, which means a more robust civilian component of subject matter experts in reconstruction, development, governance, rule of law and counter-narcotics. A greater civilian role is also key to facilitating greater Afghan ownership at the local level.

In the field of reconstruction, PRTs support development priorities set out by the GoA in line with ANDS priorities, while supporting the G-8 lead nations with their SSR tasks. Helping extend humanitarian assistance, develop dialogue with provincial leaders, strengthen local governance are among other well known PRT tasks.

While military tasks are being performed by ISAF, NATO's Senior Civilian Representative (SCR) for Afghanistan helps ensure that ISAF's mission is embedded in NATO's wider political engagement, while facilitating complementarity between NATO's efforts and those of other international organizations in support of the GoA and the Afghanistan Compact. The SCR is thus a key enabler for NATO's contribution to the wider engagement of the International Community in Afghanistan. In particular, his involvement in facilitating cooperation and coordination between NATO, the United Nations, the European Union and the G-8 lead nations has helped make the Comprehensive Approach a tangible, if still imperfect, reality in Kabul. The SCR also 
functions as a direct channel of communication between the GoA and NATO HQ in Brussels.

The third leg in this triad is, as mentioned earlier, a special program of cooperation agreed between Afghanistan and NATO in September 2006 - the Declaration by NATO and the Islamic Republic of Afghanistan on a 'Framework for Enduring Cooperation in Partnership.' The main areas of cooperation covered include defense reform, training, education and public diplomacy. They were built on the principle of Afghan ownership and complementary with ISAF's operational role. They take into consideration the activities and cooperation programs carried out by other actors in the field, to avoid wasteful duplication.

Against the background of lessons learned from NATO's engagement in Afghanistan described above, NATO's method for developing its further contribution to a wider Comprehensive Approach in Afghanistan involves both an internal and an external dimension.

On the internal side, there are four key challenges.

The first challenge is to ensure that ISAF has the military assets and capabilities necessary to perform its mission effectively, including an expanding task to train and mentor the ANA, including in the use of equipment transferred from NATO and Partner nations to the ANA through the good offices of the Alliance acting as a clearing house for equipment donations. Today ISAF has most of the capabilities it requires, but not all. In particular, ISAF is missing sufficient maneuver forces, trainers, and mobility assets, such as transport helicopters. Furthermore, NATO needs to look into the longer term and ensure that ISAF's overall level of capability is maintained through successive rotations. In this regard, we need to be certain that we have a fully manned ISAF headquarters and that the composite HQ model adopted in 2006 truly meets our longer-term needs. Work is ongoing to amend the command and control structure of HQ ISAF, that will enable it to better discharge its tasks, while enhancing ISAF's operational partnership with the ANSF in full transparency with US-led coalition forces operating under the aegis of Operation Enduring Freedom.

The second challenge is to facilitate civil-military interaction on the ground by making sure that the civilian component of PRTs is as well staffed as the military component. NATO has been working hard to ensure that PRTs have a footprint across Afghanistan, but also that they are properly resourced with civilian experts. This is not yet achieved in all PRTs. The Afghan Government would like to see PRTs in all the provinces, however it has been a challenge to fulfill that request. Currently, NATO looks for nations that would be prepared to establish PRTs in the provinces of Nimroz and Dai Kundi.

The third challenge is to ensure that our military engagement through ISAF is supported as effectively as possible by the NATO SCR in Kabul. This means strengthening the mandate and staff of the SCR, in order to empower him to play a greater diplomatic and advisory role in concert with COMISAF vis-à-vis the GoA, embassies of ISAF nations in Kabul, the United Nations, the European Union, NGOs and the local and international media. 
The fourth challenge is related to information and public diplomacy policies. This is an important, if often overlooked dimension of any successful Comprehensive Approach. NATO, the Afghan Government and the International Community have a determined and astute adversary in the Taliban, that seeks out and leverages the media and the Internet. Frequently, the Afghan population is forced to act against their own interests or the interests of their nation, out of fear or intimidation by the Taliban or by Al Qaeda. Currently, NATO is in the process of implementing a comprehensive public diplomacy strategy to support the Alliance's engagement in Afghanistan. Its success will depend, in part, on additional resources, including more professional public information officers attached to ISAF, a greater audiovisual capability, and more coherent messaging and improved coordination between NATO and the GoA, as well as between NATO HQ in Brussels and the capitals of ISAF contributing nations.

Moving on to the external dimension, NATO has pursued dialogue and cooperation with other IOs in a resolute but prudent manner. In Afghanistan, there is a plethora of actors and tasks: the UN, the EU, the five G8 Security Sector Reform lead nations, bilateral agreements and, of course, NATO itself. Coordination has been facilitated by the existence of several cooperation frameworks, such as the Afghanistan Compact and the ANDS, which involve some level of institutional interaction. The Afghanistan Compact, for example, established the Joint Coordination and Monitoring Board (JCMB), which is co-chaired by the Afghan Government and the UN. The JCMB's aim and role are to ensure coordination of the implementation of the Compact. This Board considers inputs from UN agencies, international financial organizations, donors, international security forces, NGOs and representatives of civil society with regard to the implementation of the Compact. JCMB also issues periodic progress reports on the implementation of the Afghanistan Compact, as well as of the ANDS.

Another body is the Policy Action Group, established in autumn 2006 at the level of President Karzai, to provide a mechanism to steer the efforts of the GoA and the International Community, identify shortfalls, set priorities, allocate resources, and ensure transparency and synergy. Initiatives associated with the PAG include the creation of Afghan Development Zones (ADZs) in four provinces of southern Afghanistan. This year, three additional ADZs in southeastern Afghanistan were added. In addition, Headquarters ISAF has developed a stability and reconstruction database to help identify priority tasks and areas, shortfalls and potential solutions, as a means to help optimize the deployment of ISAF forces in support of wider Afghan and international efforts.

In addition to the JCMB and the PAG, there are other forums that help provide impetus to a Comprehensive Approach in Afghanistan. The predecessor to the current NATO SCR initiated the 'Group of Principals,' which brings together periodically the senior representatives of the international organizations in Kabul, together with the senior NATO and Coalition military commanders. There is also the NATO Caucus where the SCR meets with the ambassadors of NATO nations in Kabul. Lastly, there is the PRT Executive Steering Committee originally set-up by the GoA and the Combined Forces Command, Afghanistan. It provides a tool to help bring greater coherence 
to PRT operations and practices across Afghanistan. Its meetings have resulted in the development of policy recommendations to PRT lead nations, guidance to PRT operations and a PRT Handbook containing practices and guidelines.

While the Comprehensive Approach in Afghanistan is much more than a collection of various groups and committees, these bodies provide an illustration of the strength, but also the limitations of current practices. In particular, no amount of expanded coordination on the ground will make-up for the absence of enhanced dialogue, mutual information and, where appropriate, concerted planning at higher levels, in the same way that better institutional interaction is no substitute for improved cooperation in the field.

There is no contradiction in pursuing greater harmonization on the ground level and at the institutional level. True effectiveness on the ground can only be achieved if it is backed up by enhanced dialogue and harmonized planning at the institutional level. In order for this to happen, consultation and liaison mechanisms could help develop mutual awareness ahead of a crisis and to know better how each international organization plans and conducts an operation, its best practices and its lessons learned policies.

NATO has no ambition to take the lead, however, in many cases NATO has been forced to take the lead in Afghanistan at the local level because, through the PRTs, it has now a military presence across most of the country. The issue is not so much one about who should take the lead-although the NATO Secretary General has called unambiguously for an enhanced UN lead role in Afghanistan and made it clear that NATO has no ambition to play such a role-but about ensuring that the contributions of different international actors, each within its area of competence, are as effective and complementary as possible. This means, among other things, that nations need to ensure through their membership in different international organizations that these organizations do everything that is possible to harmonize their work, both at the headquarters' level and on the ground. Only then will the promise of the Comprehensive Approach start to fully bear fruit.

The key documents- the Afghanistan Compact and the Afghan National Development Strategy-provide the areas where the Afghan Government and the International Community should focus their efforts. They are the backbone of a Comprehensive Approach to which international organizations, NATO among them, provide the flesh, in concert with the Afghan authorities and people. This is, ultimately, the promise and the opportunity that is offered by the Comprehensive Approach.

For it is not enough any longer, if it ever was, to observe that there is a high level of international engagement in Afghanistan, many institutions involved, and a number of consultation forums in place. Much well-organized and efficient consultation, dialogue and, where possible, harmonized planning are needed among the various international actors in support of the Government of Afghanistan and the Afghanistan Compact. In a recent address to the UN Security Council in New York, the UN Special Representative of the Secretary General, Tom Koenigs, underscored that the need for strategic coordination of military, political and development efforts was stronger than ever. 
Afghanistan has been a challenging but also illuminating experience for NATO on the limitations that exist when a Comprehensive Approach is not pursued with the required level of resolve. Fortunately, NATO is not alone in recognizing this unsatisfactory situation, but also in acknowledging the benefits that would derive from a more concerted and comprehensive approach to stabilization and reconstruction in crisis areas. This, in itself, is heartening and a sign of much greater maturity in seeking to optimize the goodwill and capacities of the International Community. 